\title{
Nanogels with High Loading of Anesthetic Nanocrystals for Extended Duration of Sciatic Nerve Block
}

Teresa Alejo ${ }^{a, b^{*}}$, Laura Uson $^{a, b}$, Guillermo Landa ${ }^{a, b}$, Martin Prieto ${ }^{a, b}$, Cristina Yus Argón ${ }^{a, b}$, Sara Garcia-Salinas ${ }^{a, b}$, Ricardo de Miguel ${ }^{c}$, Ana Rodríguez-Largo ${ }^{c}$, Silvia Irusta $^{a, b, d, e}$, Victor Sebastian ${ }^{a, b, d, e}$, Gracia Mendoza ${ }^{d, e^{*}}$, Manuel Arruebo $^{a, b, d, e}$

${ }^{a}$ Instituto de Nanociencia y Materiales de Aragón (INMA), CSIC-Universidad de Zaragoza, Zaragoza 50009, Spain.

b Department of Chemical Engineering, University of Zaragoza, Campus Río Ebro Edificio I+D, C/ Poeta Mariano Esquillor S/N, 50018 Zaragoza, Spain.

c Department of Animal Pathology, Veterinary Faculty, University of Zaragoza, 50013 Zaragoza, Spain

${ }^{\mathrm{d}}$ Networking Research Center on Bioengineering, Biomaterials and Nanomedicine, CIBER-BBN, 28029 Madrid, Spain.

e Aragon Health Research Institute (IIS Aragón), 50009 Zaragoza, Spain.

* Corresponding authors: Teresa Alejo: teresaal@unizar.es and Gracia Mendoza: gmendoza@,iisaragon.es 


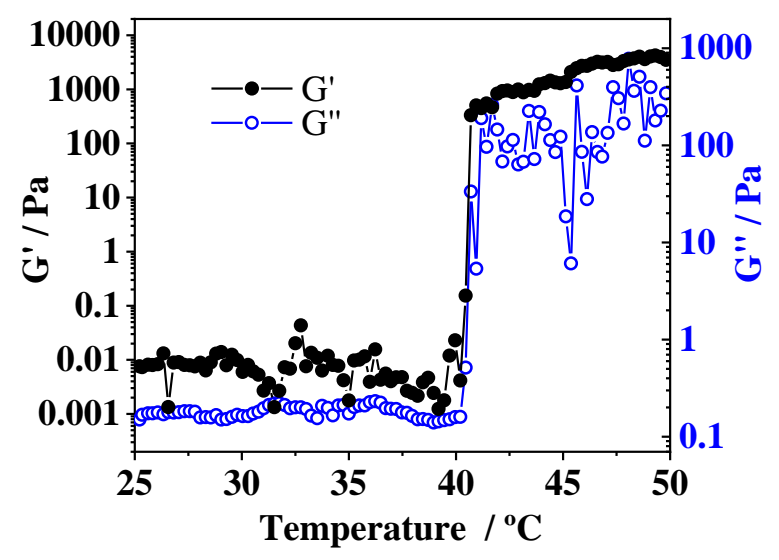

Figure S1. Dynamic temperature sweep of storage modulus G' and loss modulus G" for nanogels. The rheologically determined volume phase transition temperature is $40.5{ }^{\circ} \mathrm{C}$. 

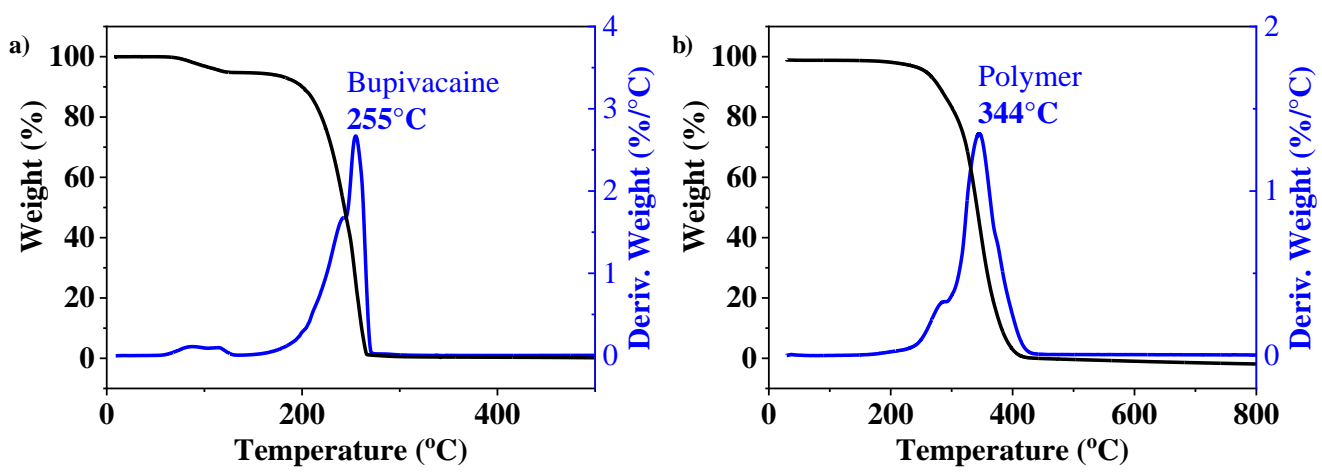

Figure S2. TGA (black) and derivative of TGA (blue) curves for (a) bupivacaine hydrochloride and (b) $\mathrm{P}\left(\mathrm{MEO}_{2} \mathrm{MA}-\mathrm{co}-\mathrm{OEGMA} 500\right)$ polymer. 
Table S1. Mathematical models' correlation coefficients and release exponents for BNC-nanogels and BNCs.

\begin{tabular}{cccc}
\cline { 3 - 4 } Kinetic model & & \multicolumn{2}{c}{ Paramosystem } \\
\hline \multirow{2}{*}{ Zero order } & $\mathrm{R}^{2}$ & 0.844 & 0.962 \\
& $\mathrm{~K}_{0}\left(\mathrm{~h}^{-1}\right)$ & 0.013 & 0.008 \\
\hline \multirow{2}{*}{ First order } & $\mathrm{R}^{2}$ & 0.833 & 0.960 \\
& $\mathrm{~K}\left(\mathrm{~h}^{-1}\right)$ & 0.014 & 0.008 \\
\hline \multirow{2}{*}{ Higuchi } & $\mathrm{R}^{2}$ & 0.961 & 0.996 \\
& $\mathrm{KH}_{\mathrm{H}}\left(\mathrm{h}^{-1 / 2}\right)$ & 0.049 & 0.027 \\
\hline \multirow{2}{*}{ Korsmeyer- } & $\mathrm{R}^{2}$ & 0.998 & 0.999 \\
\multirow{2}{*}{ Peppas } & $\mathrm{KKP}_{\mathrm{KP}}\left(\mathrm{h}^{-\mathrm{n}}\right)$ & 0.884 & 0.963 \\
& $\mathrm{n}$ & 0.041 & 0.021 \\
\hline \multirow{2}{*}{ Hixson-Crowell } & $\mathrm{R}^{2}$ & 0.837 & 0.961 \\
& $\mathrm{~K}_{\mathrm{HC}}\left(\mathrm{h}^{-\mathrm{n}}\right)$ & -0.005 & -0.003 \\
\hline
\end{tabular}



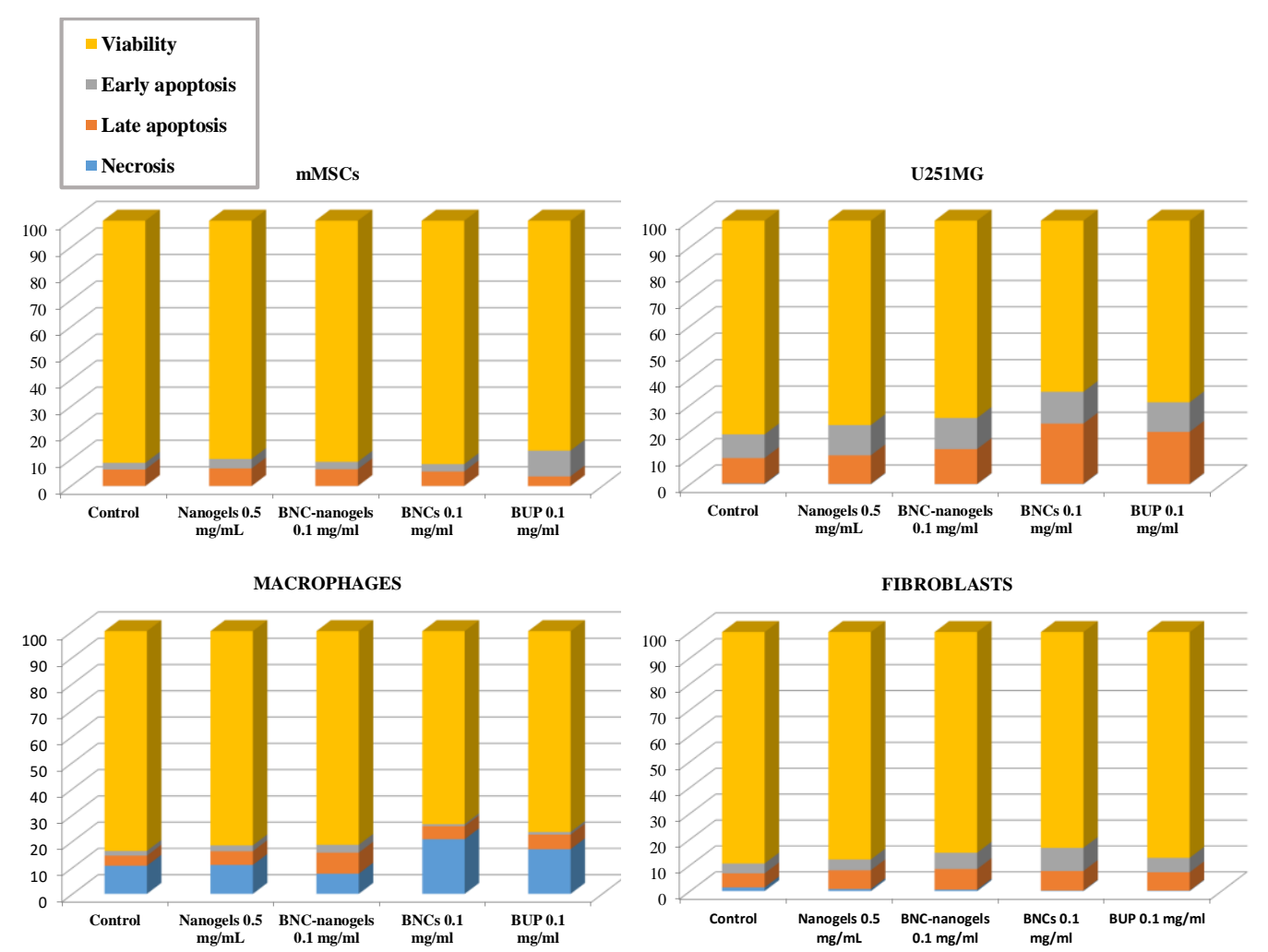

Figure S3. Percentages of both early and late apoptotic, alive and necrotic cells after treatment with empty drug-free nanogels, BNC-nanogels, BNCs, and bupivacaine hydrochloride for $24 \mathrm{~h}$. 


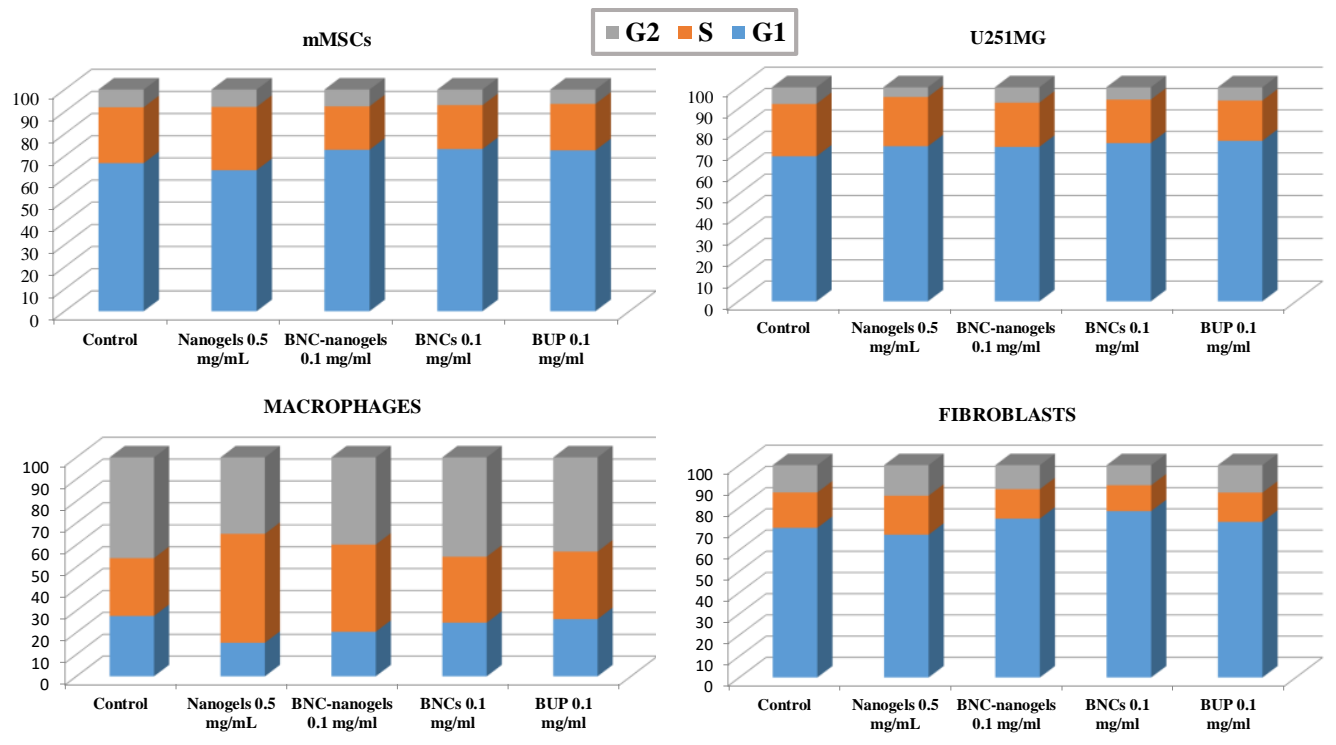

Figure S4. Cell cycle population distribution (percentage of cells, \%) after treatment with empty drug-free nanogels, BNC-nanogels, BNCs, and bupivacaine hydrochloride for 24 h. 

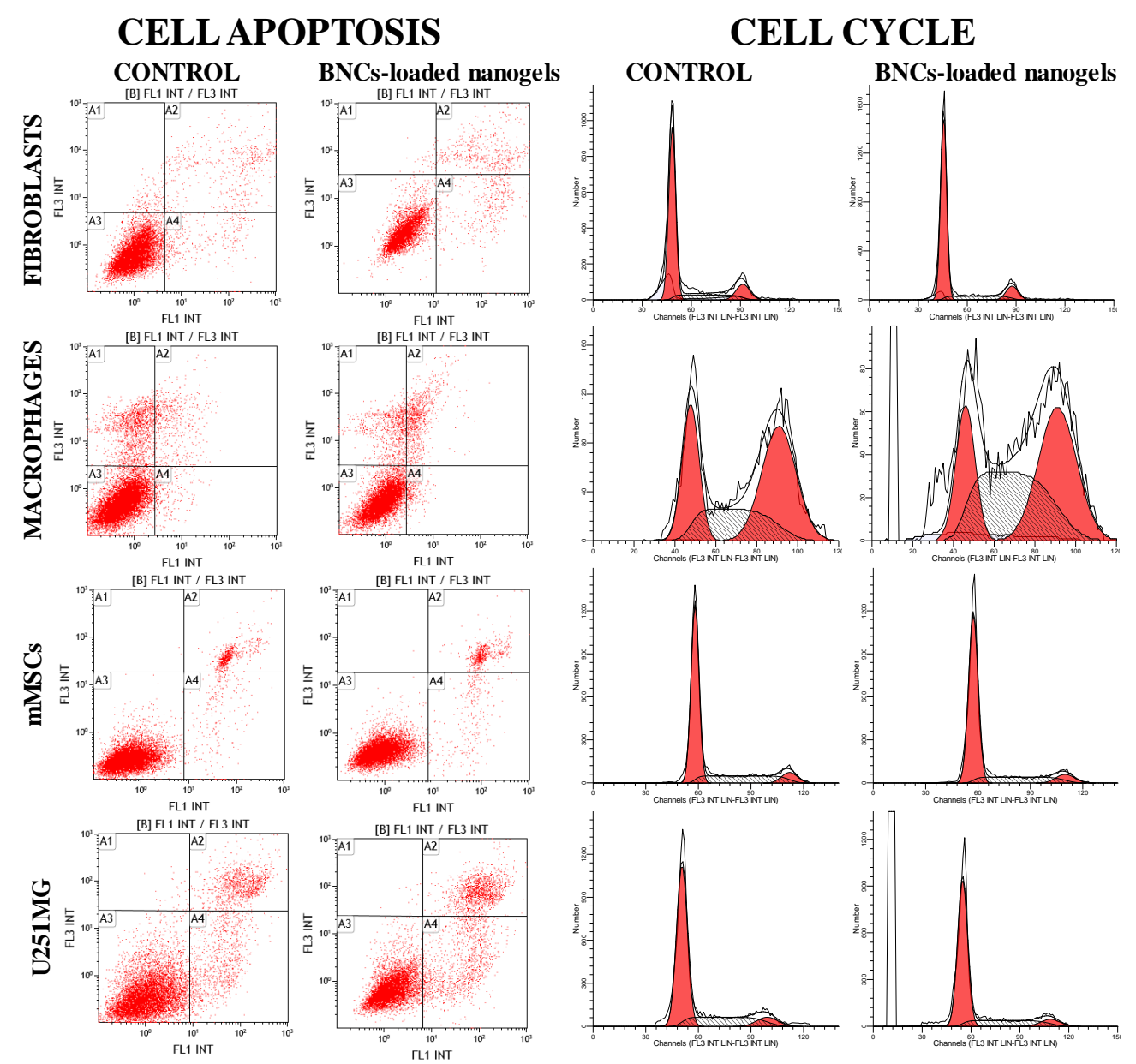

Figure S5. Flow cytometry histograms of cell apoptosis and cell cycle obtained for the control samples and the samples treated with BNC-nanogels in the four cell lines assayed. 